Review

\title{
GLP-2: What do we know? What are we going to discover?
}

\author{
Sara Baldassano *, Antonella Amato \\ Dipartimento di Scienze e Tecnologie Biologiche, Chimiche e Farmaceutiche [STEBICEF], Italy
}

\section{A R T I C L E I N F O}

\section{Article history:}

Received 14 April 2014

Received in revised form 22 August 2014

Accepted 3 September 2014

Available online 16 September 2014

\section{Keywords:}

GLP-2

GLP-2 receptor

The gastrointestinal tract

The enteric nervous system

\begin{abstract}
A B S T R A C T
Glucagon-like peptide 2 [GLP-2] is a 33-amino acid peptide released from the mucosal enteroendocrine L-cells of the intestine. The actions of GLP-2 are transduced by the GLP-2 receptor [GLP-2R], which is localized in the neurons of the enteric nervous system but not in the intestinal epithelium, indicating an indirect mechanism of action. GLP-2 is well known for its trophic role within the intestine and interest in GLP-2 is now reviving based on the approval of the GLP-2R agonist for treatment of short bowel syndrome [SBS]. Recently it also seems to be involved in glucose homeostasis.

The aim of this review is to outline the importance of neuroendocrine peptides, specifically of GLP-2 in the enteric modulation of the gastrointestinal function and to focus on new works in order to present an innovative picture of GLP-2.
\end{abstract}

(c) 2014 Elsevier B.V. All rights reserved.

\section{Contents}

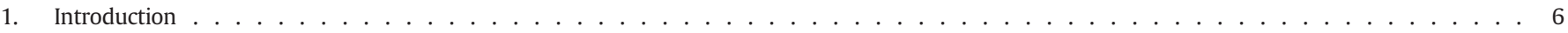

2. GLP-2 as a neuroendocrine signal from the gastrointestinal tract . . . . . . . . . . . . . . . . . . . . . . . 7

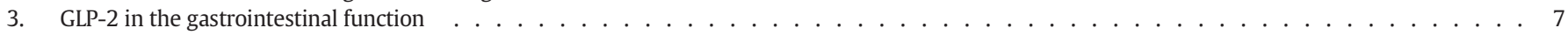

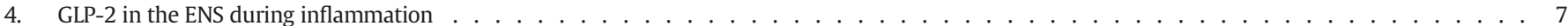

5. An innovative picture of $\mathrm{GLP}-2 \ldots \ldots \ldots \ldots \ldots$

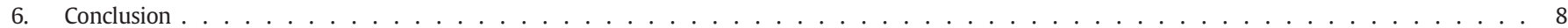

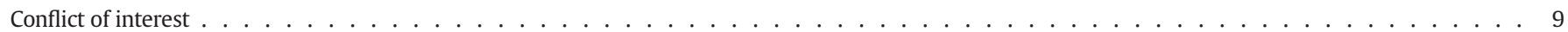

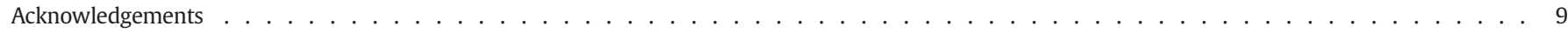

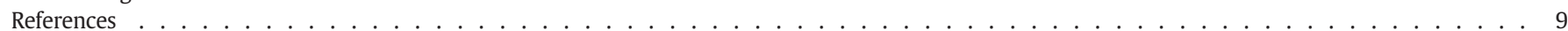

\section{Introduction}

Most of the currently known gut hormones were discovered in the 1980s [1]. However, glucagon-like substances in extracts of intestinal mucosa had already been described in 1948 [2]. Up to now hormones continue to be intensely studied such as the products of proglucagnon including glucagon, oxyntomodulin [OXM] and proglucagon derived peptides 1 [GLP-1], and 2 [GLP-2]. [3]. Glucagon is a counterregulatory hormone to insulin and acts in response to hypoglycemia while GLP-1 is a potent incretin hormone which also inhibits glucagon secretion [3,4]. GLP-1, in addition to inducing the secretion of insulin, has been shown to have biological effects on the gastrointestinal

\footnotetext{
* Corresponding author at: Dipartimento di Scienze e Tecnologie Biologiche, Chimiche e Farmaceutiche [STEBICEF], Laboratorio di Fisiologia, Università di Palermo, Viale delle Scienze, 90128 Palermo Italy. Tel.: + 3991 23897507; fax: + 39916577501.

E-mail address: sarabaldassano@gmail.com (S. Baldassano).
}

functions in both animals [5-7] and humans [8-10]. Glucagon and GLP-1 have been studied more than OXM and GLP-2, probably because of their role in the regulation of glucose homeostasis. Anyway, both OXM and GLP-2 have interesting biology. OXM seems to be a dual agonist of both the glucagon-like peptide-1 receptor (GLP1R) and the glucagon receptor (GCGR) and is involved in energetic and glucose metabolism. It lowers food intake, increases energy expenditure and improves glucose metabolism [11]. However, the mechanisms of actions are not fully understood and it is still unclear if additional $\mathrm{G}$ - protein-coupled receptors are engaged in the lowering of body weight and glucose as well as GCGR and GLP-1R. Thus, further studies are required to completely understand the mechanism of action.

GLP-2 is well known for its trophic role within the intestine [12] and interest in GLP-2 is now reviving, based on the approval of the GLP-2R agonist for treatment of short bowel syndrome [SBS] [13]. Recently it also seems to be involved in the maintaining of glucose homeostasis $[14,15]$. However, GLP-2 plays a multifaceted role within the intestine [16] and the overwhelming interest attracted by GLP-2 as a trophic 
factor has somewhat clouded the importance of the peptide in other gastrointestinal processes.

This review focuses on the recent insights into the action of GLP-2 involving the enteric nervous system [ENS] in order to outline its importance in the neural modulation of the gastrointestinal function and to present an innovative picture of GLP-2 after the approval, by the European Medicines Agency and the US Food and Drug Administration, of the GLP-2R agonist, teduglutide.

\section{GLP-2 as a neuroendocrine signal from the gastrointestinal tract}

GLP-2 belongs to the GI hormone class and more specifically it is a 33-amino acid peptide that is secreted following nutrient ingestion by the intestinal endocrine $L$ cell through the cleavage of proglucagon prohormone convertase $1 / 3$. The GLP-2 action is initiated by binding to its specific receptor, the GLP-2R that belongs to the class of seven transmembrane- $G$ protein-coupled receptors [16] and determines the activation of cAMP protein Kinase -dependent pathway [17]. However, GLP-2R has the ability to couple to different G protein subunits and to activate multiple signalling pathways [18]. Studies using cells that naturally express the receptor suggest that phosphatidylinositol 3-kinase$\gamma[\mathrm{PI} 3 \mathrm{~K} \gamma]$ and subsequent Akt phosphorylation are the intracellular pathways activated by GLP-2 $[19,20]$. The enteric nervous system seems to be a key component in the GLP-2 action, and this was initially evident for one of the GLP-2's main activities, namely its ability to enhance intestinal epithelial growth. The enteric neurons express the receptor [21-24] and the GLP-2R activation is able to stimulate gut epithelial growth and repair. In fact, the signal is transduced by the GLP-2R on enteric neurons and is then transmitted back to the epithelium [23]. On the contrary, in a model of partial enteric nervous deficit, the glial cell line-derived neurotropic factor family receptor alpha [2] [GFR $\alpha 2$ ] knockout mouse, the loss of GFR $\alpha 2$ did not affect its trophic action [25], suggesting that a functional ENS is not essential to preserve this activity. However, compensation in a transgenic model is common. Thus, it may also be possible that compensatory mechanisms are triggered.

The GLP-2R is expressed by myofibroblasts [26] and it was hypothesized that GLP-2 exerts its trophic actions indirectly through myofibroblasts as well. Indeed, GLP-2 signalling induces the release of several growth factors such us insulin-like growth factor-1 and keratinocyte growth factor, that are responsible for the proliferative effects of GLP-2.

\section{GLP-2 in the gastrointestinal function}

The presence of GLP-2R in the ENS [21-24] has suggested that some of the GLP-2 actions within the gut may not be direct in the regulation of the gastrointestinal [GI] function.

Later studies have confirmed that GLP-2 affects gut motor activity through modulation of the ENS $[27,28]$ with the final purpose of slowing motility in order to contribute and promote intestinal absorption. In the mouse small intestine GLP-2 reduces the spontaneous smooth muscle activity by increasing nitric oxide releases [22] while in the colon, where the GLP-2R is expressed and colocalized with acetylcholine -IR neurons of the myenteric plexus, the peptide acts by slowing the motility through inhibition of acetylcholine release from enteric neurons [28] suggesting a paracrine mechanism of action. A functional ENS seems to be essential for the GLP-2 motor action. Therefore, in the model of partial enteric nervous deficit, the [GFR $\alpha 2$ ] knockout mouse, GLP-2 was not able to inhibit GI transit [25].

In the mouse stomach, in vitro, the exogenous administration of GLP-2 induces gastric relaxation by neural prejunctional release of vasoactive intestinal polypeptide [VIP], leading to an increase in the stomach capacity. The effect is confined to the fundus [27]. The GLP-2 action on gastric fundus seems particularly interesting because it could represent a signalling of satiety which well fits in with the finding that GLP-2 is a chemical mediator inhibiting rodent feeding behaviour [29,30]. Thus, it is likely that the GLP-2 ability to decrease gastric motility, apart from delaying the flow through the pylorus and prolonging the gastric emptying time, may also be part of the premature inhibition of further ingestion as it constitutes a prandial satiety signal. Gastric distension inhibits food intake via vagal afferent neurons through mechanisms independent of nutrient status and the GLP-2R is localized in the cell bodies of vagal afferents in the nodose ganglion [31,32]. This idea is also supported by the finding that in pigs, GLP-2 is able to reduce the vagally induced antral motility [33]. However, its effect on gastric emptying in humans appears minimal [34]. Moreover, although the peripheral administration of GLP-2 reduces short term food intake in mice [29], it is still unclear if this effect can be related to its action within the GI tract. By peripheral administration, the neuropeptides label the blood-brain barrier-free area postrema and diffuse into the adjacent regions [35]. GLP-2R is expressed also in key regions of the brain including the hypothalamus and the hippocampus $[30,36]$. In the hypothalamus the activation of the GLP-2R reduces gastric emptying probably through the melanocortin system [37].

It is interesting to note that diet induced obese mice are less sensitive to the GLP-2 mediated short term reduction of food intake [29]. They also display increased levels of the plasma peptide [38] and of the GLP-2R expression in the stomach [39]. These results suggest that a deregulation of the GLP-2/GLP-2R system following chronic high fat diet probably occurs.

The peptide also affects the secretory function of the GI tract. In humans, GLP-2 is capable of inhibiting both pentagastrin-stimulated and sham feeding-stimulated human gastric acid secretion [40,41], likely counteracting the parasympathetic stimulation of the stomach. In the guinea pig GLP-2 modulates enteric mucosal chloride secretion. Specifically, in the small intestine GLP-2 acts on the GLP-2R, expressed in the submucosal plexus, to suppress acetylcholine release. This action of GLP-2 reduces the liquidity in the intestinal lumen by decreasing the secretion of $\mathrm{NaCl}$ and $\mathrm{H}_{2} \mathrm{O}$ [21]. Thus, GLP-2 is likely to act in a paracrine mode to influence intestinal function, via ENS and in a hormonal mode to influence gastric function.

\section{GLP-2 in the ENS during inflammation}

GLP-2 protects the ENS during mucosal inflammation [42,43]. Usually, during intestinal inflammation there is a decrease in the numbers of submucosal and myenteric neurons and changes to enteric glial cells within the enteric ganglia. These acute changes in neuronal cell numbers are accompanied by changes in specific neuronal activity, including the integrated motor and secretory functions of the intestine [44]. GLP-2 in this state is able to enhance survival of the enteric neurons in culture and to counteract mast cell induced neuronal cell death [45]. Moreover, in a culture of submucosal plexus neurons, GLP-2 is able to influence the profile of expression of the enteric neurons [46]. This suggests that GLP-2-induced neuroprotection of enteric neurons is mediated by direct stimulation of neuronal GLP-2R. However, experimental evidence has led to the proposal that GLP-2 effects could involve different indirect mediators and diverse signalling pathways [47]. One such mediator in both physiological and inflammatory conditions is VIP $[27,42,43]$. GLP-2 reduces intestinal mucosal inflammation by activation of VIP neurons in the submucosal plexus independent of any proliferative effects [43]. It restores the enteric neuronal populations to normal and influences the number and proportion of VIP-expressing neurons within the colonic submucosal plexus in vivo [42]. The GLP-2 ability to stimulate a neuronal phenotype, increasing VIP expression in primary culture of cells deriving from the submucosal plexus [46] has led to the idea that GLP-2 might also be involved in regulating the development of the ENS. In fact, a high level of expression of both hormone and receptor has been shown in the immature gut of human infants and mouse models in the later phases of gestation, when intestinal development is maximal $[48,49]$. Thus, it is possible to speculate that a deficit in GLP-2 production could be involved 
in an improper development of ENS. The GLP-2- mediated neuroprotective effects have also been demonstrated on hippocampal neurons [50]. Therefore, in consideration of the GLP-2 ability to promote survival in different types of neurons, the next step to propose is to test the GLP-2 effect on a model of neurodegenerative diseases, such as Alzheimer disease.

Apart from GLP-2 protective action on the ENS during mucosal inflammation, other studies have shown that GLP-2 is a protective signalling in other areas during inflammatory state. For example, chronic GLP-2 treatment lowers metabolic endotoxemia and hepatic inflammatory tone in genetically obese mice. It reduces plasma LPS and decreases levels of circulating proinflammatory cytokines as well as tissue markers of oxidative stress and macrophage inflammation, while the treatment with the GLP-2R antagonist, GLP-2 (3-33), exacerbates the inflammatory condition [51].

\section{An innovative picture of GLP-2}

The scientific understanding of GLP-2 has highlighted its central role as trophic regulator of mucosal function [12] and has led to the recent approval by the European Medicines Agency and the U.S. Food and Drug Administration of teduglutide, the long acting agonist of GLP-2 for the treatment of SBS [13]. This is providing patients with SBS with an addition to the present limited treatment, currently consisting mainly of anti-diarrhoeal and anti-secretory medications.

As GLP-2 is a potent and specific gastrointestinal growth factor, the recent studies in the field are looking further into the characterization of its action in experimental settings reproducing different intestinal pathologies in different ages in which the intestinal pathologies occur. Apart from GLP-2 itself, studies are focusing on the effects of teduglutide and of the inhibitor of its degradation, dipeptidyl peptidase-4.

Due to its action of enhancing cellular growth, one of the main concerns is about the possibility that GLP-2 analogue may also stimulate the growth of malignant cells [52,53]. A study conducted in patients with intestinal failure associated with short bowel syndrome showed that 6 months teduglutide treatment enhanced the structural adaptation of the small intestinal mucosa without indications of dysplastic transformation [54]. Thus, this study encourages therapeutic use of the drug to reduce dependence on parenteral nutrition without the risk of developing dysplasia although a 6 month course of treatment is a relatively short time. Thus, long-term surveillance studies are needed to exclude potential adverse outcomes.

Another issue is about the importance of characterizing the GLP-2 effects on intestinal pathologies in the early stages of life because a number of these conditions occur in newborn babies and infants that are very different from adults in their disposition and response to drugs [55]. Moreover, it is imperative to verify if GLP-2 by stimulating mucosal proliferation also encourages the growth of malignant cells in children because they potentially might need the treatment over a longer period of time. Besides, in consideration of its effects as an anorectic factor, in animal models [30,35], experiments to verify if at an early age it affects appetite and/or behaviour are mandatory in order to guide the correct development of therapeutic applications in the different stages of life. A study about the therapeutic application of GLP-2 in early life conducted on newborn pigs is encouraging. It showed that the exogenous administration of GLP-2 stimulates small intestinal growth during weaning in neonatal pigs without polyps or unusual growths in the intestine [56]. It is of interest to note that the authors administered a dose of $40 \mu \mathrm{g} / \mathrm{kg} / \mathrm{day}$, in two subcutaneous injections a day, which is twice that of a pharmacological dose of GLP-2 used in the majority of adult human trials [57-60]. They reported that the effects were limited to the gastrointestinal tract and it was well tolerated with no measurable changes in activity, growth, development, renal and hepatic function, or growth in non-gastrointestinal tissues [56]. Although this study is quite promising, the relatively short period of treatment, 42 days, should be considered and the potential side effects of prolonged treatment explored.
Another interesting study verified the potential applicability of teduglutide in improving intestinal adaptation in paediatric patients with short bowel syndrome. They used newborn piglet jejunostomy models that mimic newborn human short bowel syndrome following gut resection [61]. They reported that after 7 days of daily injections with teduglutide (doses from $0.01 \mathrm{mg} / \mathrm{Kg} / \mathrm{day}$ to $0.2 \mathrm{mg} / \mathrm{Kg} /$ day) the trophicity of the intestine was increased but the effects on mucosal function were limited. Indeed, teduglutide treatment did not increase the activity of digestive enzymes and the absorption of enteral nutrients. The study is a good starting point because it indicates that 7 days of treatment in infants is sufficient for intestinal morphological adaptation but not enough to improve the gut function.

Although teduglutide has been approved by the European Medicine and the U.S. Food and Drug Administration for the treatment of SBS [13], and is in clinical trials for Crohn's Disease [62] studies with humans are still limited. A study conducted in paediatric patients with acute ileal Crohn disease (CD) reported reduction in postprandial GLP-2 release with potential consequence on nutrient absorptive capacity [63]. Thus, this study suggests that the inflammatory states reduce GLP-2 mealstimulated release. Unfortunately, the GLP-2 release mechanisms are not fully understood and deserve further studies. What is known, is that the stimulus for the early postprandial peak is neural mediated. In fact, in rats, vagotomy prevents stimulation of L cells by fat, while direct activation of the celiac branch of the vagus increases secretion [64]. The direct contact of luminal nutrients with $\mathrm{L}$ cells induces the second peak of GLP-2 secretion [65]. Over time it has been observed that patients with intestinal inflammation have changes in the pattern of encoding neurons $[66,67]$ which may be signalled by a reduction in ongoing endogenous GLP-2. Therefore, it is priority to fully elucidate the release mechanism of native GLP-2 in order to optimize it. Moreover, it is essential to explore the influence of the modification of the diet content on GLP-2 secretion to see if and to what extent it is affected and to assess its influence on the plasticity of ENS. This might be of interest for the development of therapeutic strategies in patients who have acute inflammation such as CD.

GLP-2 capacity to enhance barrier function is an interesting characteristic because very few known drugs or therapies can reduce gut leakiness [68]. However, to improve its therapeutic application, the action mechanism on barrier function should be fully elucidated. As the GLP$2 \mathrm{R}$ does not localize to the target tissue such as crypt epithelium and enterocytes [13] it requires mediators to exert its trophic actions. Recently, the intestinal epithelial insulin like growth factor 1 receptor (IE-IGF-1R) has been found to act as a mediator [69]. Indeed, 10 days treatment of mice with $0.1 \mu \mathrm{g} / \mathrm{g}$ of $\mathrm{h}\left(\mathrm{Gly}^{2}\right) \mathrm{GLP}-2$, a pharmacological dose of a degradation-resistant GLP-2 analogue, reduced the gastrointestinal permeability in control mice with increased expression of the sealing proteins claudin-3 and 7 but not in IE-IGF-1R null mice strongly suggesting its involvement in the GLP-2 action.

In the new picture of GLP-2 it is interesting to point out the involvement of the neuroendocrine signal in the glucose homeostasis. Barhami and Coll. reported that in genetically obese mice elimination of GLP-2R signalling impaired the normal islet adaptative response required to maintain glucose homeostasis [15] while the study of Shi and Coll. [14] showed that the GLP-2R deletion in pro-opiomelanocortin [POMC] neurons impairs postprandial glucose tolerance and hepatic insulin sensitivity. These studies strongly suggest that endogenous GLP-2 is functionally important for glucose homeostasis although future studies, for example, using chronic treatment with the GLP-2R antagonist to block the endogenous GLP-2 action instead of knockout models, that could activate compensatory mechanism, are mandatory.

\section{Conclusion}

The study of GLP-2 has led to innovative treatment in conditions of intestinal injury such as SBS. It can be considered as a unique enteroendocrine hormone for its activity as a specific intestinal growth 
factor. In this review, we have focused on the action of the GLP-2 within the gut that involves the ENS in the attempt to shed more light on the link between GLP-2 and the activity and overall function of the ENS. Moreover, we have pointed out what has been achieved following the approval of teduglutide and what should be done in order to improve its application. We have focused on ENS because we considered its action potentially important in the regulation of the function in the GI tract as well as the protective effects of GLP-2 on neuron growth and phenotype. With the spread of gastrointestinal dysfunction on the rise, to clarify these kinds of effects and to analyze the mechanism of action and possible other interaction, it may be important to understand the intestinal function better both at the physiological and the pathophysiological states. Many questions remain to be answered and one of these is whether the normal postprandial release of GLP-2 may signal a physiological effect on enteric neuronal populations, as well as the GLP-2 involvement in glucose homeostasis.

\section{Conflict of interest}

The authors declare that there are no conflicts of interest.

\section{Acknowledgements}

This work was supported by MIUR, Italy.

\section{References}

[1] Dockray GJ. Gastrointestinal hormones. In: Johnson LR, Barret KE, Gishan FK, Merchant JL, Said HM, Wood JD, editors. Physiology of the gastrointestinal tract. New York: Raven; 2006. p. 91-120.

[2] Holst JJ. Gut glucagon, enteroglucagon, gut glucagon-like immunoreactivity glicentin current status. Gastroenterology 1983;84:1602-13.

[3] Holst JJ. Enteroglucagon. Annu Rev Physiol 1997;59:257-71.

[4] Holst JJ. Glucagon-like peptide-1 [GLP-1] a newly discovered GI hormone. Gastroenterology 1994;107:1848-55.

[5] Baldassano S, Wang GD, Mulè F, Wood JD. Glucagon-like peptide-1 modulates neurally evoked mucosal chloride secretion in guinea pig small intestine in vitro. Am J Physiol Gastrointest Liver Physiol 2012;302:G352-8.

[6] Rotondo A, Amato A, Lentini L, Baldassano S, Mulè F. Glucagon-like peptide-1 relaxes gastric antrum through nitric oxide in mice. Peptides 2011;32:60-4.

[7] Tolessa T, Gutniak M, Holst JJ, Efendic S, Hellstrom PM. Glucagon-like peptide-1 retards gastric emptying and small bowel transit in the rat. Dig Dis Sci 1998;43: 2284-90.

[8] Amato A, Baldassano S, Liotta R, Serio R, Mule F. Exogenous glucagon-like peptide-1 reduces contractions in human colon circular muscle. J Endocrinol 2014;221:29-37.

[9] Wettergren A, Wojdemann M, Holst JJ. Glucagon-like peptide-1 inhibits gastropancreatic function by inhibiting central parasympathetic outflow. Am J Physiol 1998;275:G984-92.

[10] Tolessa T, Gutniak M, Holst JJ, Efendic S, Hellstrom PM. Inhibitory effect of glucagonlike peptide-1 on small bowel motility. J Clin Invest 1998;102:764-74.

[11] Pocai A. Unraveling oxyntomodulin, GLP1's enigmatic brother. J Endocrinol 2012; 215:335-46.

[12] Estall JL, Drucker DJ. Glucagon-like peptide-2. Annu Rev Nutr 2006;26:391-411.

[13] Jeppesen PB. Teduglutide for the treatment of short bowel syndrome. Drugs Today 2013;49:599-614.

[14] Shi X, Zhou F, Li X, Chang B, Li D, Wang Y, et al. Central GLP-2 enhances hepatic insulin sensitivity via activating PI3K signaling in POMC neurons. Cell Metab 2013;18: 86-98.

[15] Bahrami J, Longuet C, Baggio LL, Li K, Drucker DJ. Glucagon-like peptide-2 receptor modulates islet adaptation to metabolic stress in the ob/ob mouse. Gastroenterology 2010;139:857-68.

[16] Dubé PE, Brubaker PL. Frontiers in glucagon-like peptide-2: multiple actions, multiple mediators. Am J Physiol Endocrinol Metab 2007;293:E460-5.

[17] Walsh NA, Yusta B, DaCambra MP, Anini Y, Drucker DJ, Brubaker PL. Glucagon-like peptide-2 receptor activation in the rat intestinal mucosa. Endocrinology 2003; 144:4385-92.

[18] Koehler JA, Yusta B, Drucker DJ. The HeLa cell glucagon-like peptide-2 receptor is coupled to regulation of apoptosis and ERK1/2 activation through divergent signaling pathways. Mol Endocrinol 2005;19:459-73.

[19] Leen JL, Izzo A, Upadhyay C, Rowland KJ, Dube PE, Gu S, et al. Mechanism of action of glucagon-like peptide-2 to increase IGF-I mRNA in intestinal subepithelial fibroblasts. Endocrinology 2011;152:436-46.

[20] Shi X, Li X, Wang Y, Zhang K, Zhou F, Chan L, et al. Glucagon-like peptide-2stimulated protein synthesis through the PI 3-kinase-dependent Akt-mTOR signaling pathway. Am J Physiol Endocrinol Metab 2011;300:E554-63.
[21] Baldassano S, Liu S, Qu MH, Mulè F, Wood JD. Glucagon-like peptide-2 modulates neurally evoked mucosal chloride secretion in guinea pig small intestine in vitro. Am J Physiol Gastrointest Liver Physiol 2009;297:G800-5.

[22] Cinci L, Faussone-Pellegrini MS, Rotondo A, Mulè F, Vannucchi MG. GLP-2 receptor expression in excitatory and inhibitory enteric neurons and its role in mouse duodenum contractility. Neurogastroenterol Motil 2011;23:e383-92.

[23] Bjerknes $M$, Cheng H. Modulation of specific intestinal epithelial progenitors by enteric neurons. Proc Natl Acad Sci U S A 2001;98:12497-502.

[24] Guan X, Karpen HE, Stephens J, Bukowski JT, Niu S, Zhang G, et al. GLP-2 receptor localizes to enteric neurons and endocrine cells expressing vasoactive peptides and mediates increased blood flow. Gastroenterology 2006;130:150-64.

[25] McDonagh SC, Lee J, Izzo A, Brubaker PL. Role of glial cell-line derived neurotropic factor family receptor alpha2 in the actions of the glucagon-like peptides on the murine intestine. Am J Physiol Gastrointest Liver Physiol 2007;293:G461-8.

[26] El-Jamal N, Erdual E, Neunlist M, Koriche D, Dubuquoy C, Maggiotto F, et al. Glugacon-like peptide-2: broad receptor expression, limited therapeutic effect on intestinal inflammation and novel role in liver regeneration. Am J Physiol Gastrointest Liver Physiol 2014;307:G274-85.

[27] Amato A, Baldassano S, Serio R, Mulè F. Glucagon-like peptide-2 relaxes mouse stomach through vasoactive intestinal peptide release. Am J Physiol Gastrointest Liver Physiol 2009;296:G678-84.

[28] Amato A, Rotondo A, Cinci L, Baldassano S, Vannucchi MG, Mulè F. Role of cholinergic neurons in the motor effects of glucagon-like peptide- 2 in mouse colon. Am J Physiol Gastrointest Liver Physiol 2010;299:G1038-44.

[29] Baldassano S, Bellanca AL, Serio R, Mulè F. Food intake in lean and obese mice after peripheral administration of glucagon-like peptide 2. J Endocrinol 2012;213:277-84.

[30] Tang-Christensen M, Larsen PJ, Thulesen J, Rømer J, Vrang N. The proglucagonderived peptide, glucagon-like peptide-2, is a neurotransmitter involved in the regulation of food intake. Nat Med 2000;6:802-7.

[31] Nelson DW, Sharp JW, Brownfield MS, Raybould HE, Ney DM. Localization and activation of glucagon-like peptide-2 receptors on vagal afferents in the rat. Endocrinology 2007;148:1954-62.

[32] Bucinskaite V, Tolessa T, Pedersen J, Rydqvist B, Zerihun L, Holst JJ, et al. Receptormediated activation of gastric vagal afferents by glucagon-like peptide- 1 in the rat. Neurogastroenterol Motil 2009;21:978-e78.

[33] Wøjdemann M, Wettergren A, Hartmann B, Holst JJ. Glucagon-like peptide-2 inhibits centrally induced antral motility in pigs. Scand J Gastroenterol 1998;33:828-32.

[34] Nagell CF, Wettergren A, Pedersen JF, Mortensen D, Holst JJ. Glucagon-like peptide-2 inhibits antral emptying in man, but is not as potent as glucagon-like peptide-1. Scand J Gastroenterol 2004;39:353-8.

[35] Whitcomb DC, Taylor IL, Vigna SR. Characterization of saturable binding sites for circulating pancreatic polypeptide in rat brain. Am J Physiol 1990;259:G687-91

[36] Wang Y, Guan X. GLP-2 potentiates L-type Ca2 + channel activity associated with stimulated glucose uptake in hippocampal neurons. Am J Physiol Endocrinol Metab 2010;298:E156-66.

[37] Guan X, Shi X, Li X, Chang B, Wang Y, Li D, et al. GLP-2 receptor in POMC neurons suppresses feeding behavior and gastric motility. Am J Physiol Endocrinol Metab 2012;303:E853-64.

[38] Baldassano S, Amato A, Cappello F, Rappa F, Mulè F. Glucagon-like peptide-2 and mouse intestinal adaptation to a high-fat diet. J Endocrinol 2013;217:11-20.

[39] Rotondo A, Amato A, Baldassano S, Lentini L, Mulè F. Gastric relaxation induced by glucagon-like peptide-2 in mice fed a high-fat diet or fasted. Peptides 2011;32: 1587-92.

[40] Wøjdemann M, Wettergren A, Hartmann B, Hilsted L, Holst JJ. Inhibition of sham feeding-stimulated human gastric acid secretion by glucagon-like peptide-2. J Clin Endocrinol Metab 1999;84:2513-7.

[41] Meier JJ, Nauck MA, Pott A, Heinze K, Goetze O, Bulut K, et al. Glucagon-like peptide 2 stimulates glucagon secretion, enhances lipid absorption, and inhibits gastric acid secretion in humans. Gastroenterology 2006;130:44-54.

[42] Sigalet DL, Wallace L, De Heuval E, Sharkey KA. The effects of glucagon-like peptide 2 on enteric neurons in intestinal inflammation. Neurogastroenterol Motil 2010;22: 1318-e350.

[43] Sigalet DL, Wallace LE, Holst JJ, Martin GR, Kaji T, Tanaka H, et al. Enteric neural pathways mediate the anti-inflammatory actions of glucagon-like peptide 2. Am J Physiol Gastrointest Liver Physiol 2007;293:G211-21.

[44] Mawe GM, Strong DS, Sharkey KA. Plasticity of enteric nerve functions in the inflamed and postinflamed gut. Neurogastroenterol Motil 2009;21:481-91.

[45] Voss U, Sand E, Hellström PM, Ekblad E. Glucagon-like peptides 1 and 2 and vasoactive intestinal peptide are neuroprotective on cultured and mast cell co-cultured rat myenteric neurons. BMC Gastroenterol 2012;1:12-30.

[46] de Heuvel E, Wallace L, Sharkey KA, Sigalet DL. Glucagon-like peptide 2 induces vasoactive intestinal polypeptide expression in enteric neurons via phophatidylinositol 3-kinase- $\gamma$ signaling. Am J Physiol Endocrinol Metab 2012;303:E994-1005.

[47] Rowland KJ, Brubaker PL. The "cryptic" mechanism of action of glucagonlike peptide-2. Am J Physiol Gastrointest Liver Physiol 2011;301:G1-8.

[48] Lovshin J, Yusta B, Iliopoulos I, Migirdicyan A, Dableh L, Brubaker PL, et al. Ontogeny of the glucagon-like peptide-2 receptor axis in the developing rat intestine. Endocrinology 2000;141:4194-201.

[49] Amin H, Holst JJ, Hartmann B, Wallace L, Sigalet D. Functional ontogeny of the proglucagon derived peptide axis in human neonates. Pediatrics 2008;121:e180-6.

[50] Lovshin JA, Huang Q, Seaberg R, Brubaker PL, Drucker DJ. Extrahypothalamic expression of the glucagon-like peptide-2 receptor is coupled to reduction of glutamateinduced cell death in cultured hippocampal cells. Endocrinology 2004;145:3495-506.

[51] Cani PD, Possemiers S, Van de Wiele T, Guiot Y, Everard A, Rottier O, et al. Changes in gut microbiota control inflammation in obese mice through a mechanism involving GLP-2-driven improvement of gut permeability. Gut 2009;58:1091-103. 
[52] Trivedi S, Wiber SC, El-Zimaity HM, Brubaker PL. Glucagon-like peptide-2 increases dysplasia in rodent models of colon cancer. Am J Physiol Gastrointest Liver Physiol 2012;302:G840-9.

[53] Iakoubov R, Lauffer LM, Trivedi S, Kim YI, Brubaker PL. Carcinogenic effects of exogenous and endogenous glucagon-like peptide-2 in azoxymethane-treated mice. Endocrinology 2009;150:4033-43.

[54] Tappenden KA, Edelman J, Joelsson B. Teduglutide enhances structural adaptation of the small intestinal mucosa in patients with short bowel syndrome. J Clin Gastroenterol 2013;47:602-7.

[55] Gideon K. Therapeutic drug monitoring principles in the neonate. Clin Chem 1997; 43(1):222-7.

[56] Sigalet DL, de Heuvel E, Wallace L, Bulloch E, Turner J, Wales PW, et al. Effects of chronic glucagon-like peptide-2 therapy during weaning in neonatal pigs. Regul Pept 2014;188:70-80.

[57] Henriksen DB, Alexandersen P, Hartmann B, Adrian CL, Byrjalsen I, Bone HG, et al. A four-month course of treatment with GLP-2 significantly increases hip BMD: a randomized, placebo-controlled, dose-ranging study in postmenopausal women with low BMD. Bone November 2009;45:833-42.

[58] Jeppesen PB, Hartmann B, Thulesen J, Graff J, Lohmann J, Hansen BS, et al. Glucagonlike peptide 2 improves nutrient absorption and nutritional status in short-bowel patients with no colon. Gastroenterology March 2001;120:806-15.

[59] Jeppesen PB, Lund P, Gottschalck IB, Nielsen HB, Holst JJ, Mortensen J, et al. Short bowel patients treated for two years with glucagon-like Peptide 2: effects on intestinal morphology and absorption, renal function, bone and body composition, and muscle function. Gastroenterol Res Pract 2009;2009:616054.

[60] Jeppesen PB, Lund P, Gottschalck IB, Nielsen HB, Holst JJ, Mortensen J, et al. Short bowel patients treated for two years with glucagon-like peptide 2 (GLP-2): compliance, safety, and effects on quality of life. Gastroenterol Res Pract 2009;2009: 425759.
[61] Thymann T, Stoll B, Mecklenburg L, Burrin DG, Vegge A, Ovist N, et al. Acute effects of the glucagon-like peptide 2 analogue, teduglutide, on intestinal adaptation in short bowel syndrome. J Pediatr Gastroenterol Nutr 2014;58:694-702.

[62] Blonski W1, Buchner AM, Aberra F, Lichtenstein G. Teduglutide in Crohn's disease. Expert Opin Biol Ther 2013;13:1207-14.

[63] Sigalet DL, Kravarusic D, Butzner D, Hartmann B, Holst JJ, Meddings J. A pilot study examining the relationship among Crohn disease activity, glucagon-like peptide-2 signalling and intestinal function in pediatric patients. Can J Gastroenterol 2013; 27:587-92.

[64] Rocca AS, Brubaker PL. Role of the vagus nerve in mediating proximal nutrientinduced glucagon-like peptide-1 secretion. Endocrinology 1999;140:1687-94.

[65] Brubaker PL, Anini Y. Direct and indirect mechanisms regulating secretion of glucagon-like peptide-1 and glucagon-like peptide-2. Can J Physiol Pharmacol 2003;81:1005-12.

66] Neunlist M, Toumi F, Oreschkova T, Denis M, Leborgne J, Laboisse CL et al. Human ENS regulates the intestinal epithelial barrier permeability and a tight junctionassociated protein ZO-1 via VIPergic pathways. Am J Physiol Gastrointest Liver Physiol 2003;285:G1028-36.

[67] Schneider J, Jehle EC, Starlinger MJ, Neunlist M, Michel K, Hoppe S, et al. Neurotransmitter coding of enteric neurones in the submucous plexus is changed in noninflamed rectum of patients with Crohn's disease. Neurogastroenterol Motil 2001 13:255-64.

[68] Bjarnason I, MacPherson A, Hollander D. Intestinal permeability: an overview. Gastroenterology 1995;108:1566-81.

[69] Dong CX, Zhao W, Solomon C, Rowland KJ, Ackerley C, Robine S, et al. The intestinal epithelial insulin-like growth factor-1 receptor links glucagon-like peptide-2 action to gut barrier function. Endocrinology 2014;155:370-9. 